\title{
Peptide-catalyzed 1,4-Addition Reactions of Aldehydes to Nitroolefins
}

\author{
Robert Kastl§, Yukihiro Arakawa, Jörg Duschmalé, Markus Wiesner, and Helma Wennemers* \\ §SCS-DSM Award for best poster presentation
}

\begin{abstract}
Conjugate addition reactions of aldehydes to nitroolefins provide synthetically useful $\gamma$-nitroaldehydes. Here we summarize our research on peptide-catalyzed conjugate addition reactions of aldehydes to differently substituted nitroolefins. We show that peptides of the general type Pro-Pro-Xaa (Xaa = acidic amino acid) are not only highly active, robust and stereoselective catalysts but have also remarkable chemoselectivities.
\end{abstract}

Keywords: Asymmetric catalysis · Conjugate addition reaction · Nitroolefins · Organocatalysis · Peptides

\section{Introduction}

Asymmetric conjugate addition reactions of carbon-based nucleophiles to electron-deficient olefins are among the most useful $\mathrm{C}-\mathrm{C}$ bond forming reactions. ${ }^{[1]}$ Among them the addition of aldehydes to nitroolefins is an attractive reaction, affording $\gamma$-nitroaldehydes as versatile intermediates for further transformations into, for example, chiral pyrrolidines, $\gamma$-butyrolactams or $\gamma$-amino acids (Scheme 1). [2] Over recent years several chiral amine-based catalysts have been developed for asymmetric conjugate addition reactions of aldehydes to $\beta$-substituted nitroolefins. ${ }^{[2,3]}$ With several of the catalysts high stereoselectivities are achieved, however, the poor catalytic activity typically requires the use of $10 \mathrm{~mol} \%$ or more of the catalyst. ${ }^{[2]}$ In addition, a high excess of the aldehyde is often necessary since products from homo-aldol reactions are commonly observed.

Our group became interested in whether short-chain peptides may be useful alternatives to other synthetic organocatalysts as peptides allow access to a large structural and functional diversity that might be useful for tuning the catalytic properties to the needs of the reaction. Since peptides are typically conformationally flexible the rational design of a peptidic catalyst is difficult. We therefore started our work by the development and use of the combinatorial screening method of 'catalyst-substrate co-immobilization'. ${ }^{[4]}$ This allowed the identification of tripeptides of the general type Pro-Pro-Xaa (Xaa = acidic amino acid) as versatile catalysts for enamine catalysis. ${ }^{[5,6]}$ For example, tripeptide H-ProPro-Asp- $\mathrm{NH}_{2}$ (1) proved to be a very good catalyst for direct aldol reactions ${ }^{[6,7]}$ whereas the closely related peptides H-DPro-Pro-Glu- $\mathrm{NH}_{2}$ (2) and H-Pro-Pro-DGln-OH (3) are excellent catalysts for conjugate addition reactions of aldehydes to nitroethylene ${ }^{[8]}$ and $\beta$-monosubstituted nitroolefins ${ }^{[9-14]}$ and even less reactive $\alpha, \beta$-disubstituted nitroolefins, respectively (Fig. 1). ${ }^{[15]}$ These peptides were found to have remarkable catalytic properties such as high catalytic activity and stereoselectivity, high chemoselectivity and a broad substrate scope. In addition, their modular nature, their low molecular weight and facile synthesis make these peptides attractive as synthetic catalysts. The results achieved by our group in peptide-catalyzed con- jugate addition reactions of aldehydes to nitroolefins are summarized in this article.

\section{2. $\mathrm{H}-\mathrm{D}-\mathrm{Pro}-\mathrm{Pro}-\mathrm{Glu}-\mathrm{NH}_{2}$ as a Catalyst for Conjugate Addition Reactions of Aldehydes to Nitroolefins}

Insights from molecular modeling studies with the peptidic catalyst for aldol reactions, H-Pro-Pro-Asp- $\mathrm{NH}_{2}$ (1), combined with mechanistic considerations led to the development of the related peptide H-DPro-Pro-Glu-NH $\mathrm{N}_{2}$ (2) as a catalyst for conjugate addition reactions of aldehydes to nitroolefins. ${ }^{[9-14]}$ In the presence of only $\leq 1$ mol\% of peptide 2 a broad range of different aldehydes react readily with aliphatic and aromatic $\beta$-substituted nitroolefins to form the corresponding $\gamma$-nitroaldehydes in excellent yields and stereoselectivities at room temperature (Scheme 2). ${ }^{[10,11]}$ The best results were obtained with nitroolefins bearing electron-poor aromatic substituents, however even with the poorest substrate combination (aliphatic nitroolefin and propanal) good stereoselectivities
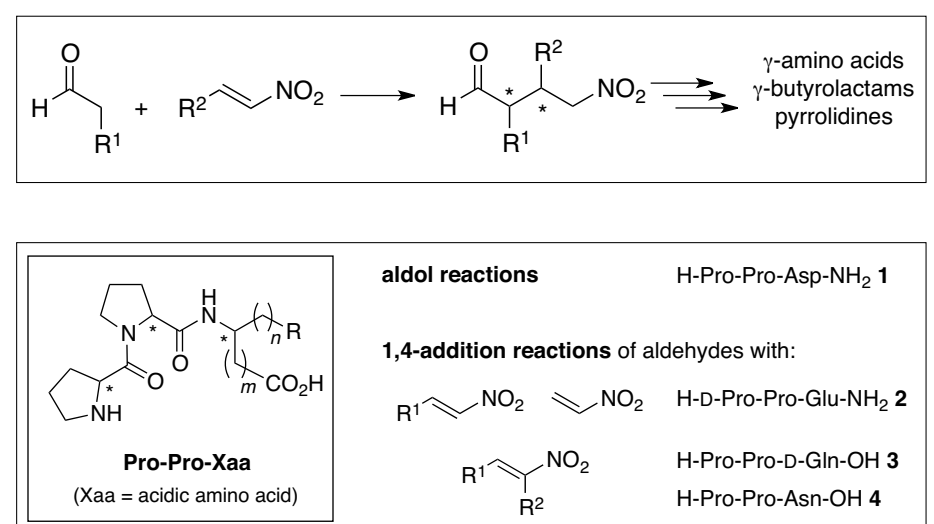

H-Pro-Pro-Asp- $\mathrm{NH}_{2} 1$

1,4-addition reactions of aldehydes with:

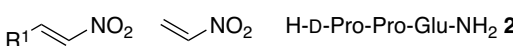
$\mathrm{R}^{1} \mathrm{NO}_{2}$ $\mathrm{R}^{2}$

H-Pro-Pro-D-Gln-OH 3 H-Pro-Pro-Asn-OH 4
Scheme 1. Conjugate addition reactions of aldehydes to $\beta$-substituted nitroolefins.

Fig. 1. Peptidic catalysts of the type ProPro-Xaa for aldol and conjugate addition reactions.
Laboratorium für Organische Chemie

Colfgang-Pauli-Str. 10

Tel.: +4144633 3777

E-mail: wennemers@org.chem.ethz.ch 
were achieved $(\mathrm{dr}=6: 1,98 \%$ ee $)$. The obtained $\gamma$-nitroaldehydes with diverse functionalities can be easily converted into further valuable compounds such as chiral $\gamma$-amino acids or $\gamma$-butyrolactams.

Even nitroethylene, the simplest of all nitroolefins that is known to polymerize easily, reacted readily with aldehydes in the presence of peptide 2 to provide access to monosubstituted $\gamma$-nitroaldehydes in high yields and enantioselectivities (Scheme 3). These allow facile conversion into monosubstituted $\gamma^{2}$-amino acids that had thus far only been accessible using chiral auxiliaries. ${ }^{[8]}$

Kinetic studies using in situ IR spectroscopy provided insight into the ratedetermining step of the peptide-catalyzed conjugate addition reaction between aldehydes and nitroolefins. ${ }^{[11,16]}$ These studies allowed further improvement of the reaction conditions by using anhydrous solvents and reagents and an excess of nitroolefin with respect to the aldehyde. Under these optimized conditions the reaction proceeds significantly faster and, most remarkably, enabled a reduction of the catalyst loading by the factor of 10 to as little as $0.1 \mathrm{~mol} \%$. The desired $\gamma$-nitroaldehydes were still obtained in excellent yields and stereoselectivities. This catalyst loading is to the best of our knowledge the lowest thus far achieved in enamine catalysis with synthetic organocatalysts.

In contrast to many other chiral secondary amine-based catalysts, peptide $\mathbf{2}$ has a high selectivity for conjugate addition reactions over competing homo-aldol reactions. ${ }^{[9-12]}$ This high chemoselectivity is particularly remarkable since the closely related peptide H-Pro-Pro-Asp- $\mathrm{NH}_{2}$ (1) is a good catalyst for aldol reactions. ${ }^{[6,7]}$ In addition no additives are necessary for the catalysis. ${ }^{[10,16]}$ Since the peptides are easily prepared by using the 9-fluorenylmethoxycarbonyl/tert-butyl (Fmoc/tBu) protocol for solid-phase peptide synthesis and therefore obtained conveniently as the trifluoroacetic acid (TFA) salts, the addition of $N$-methylmorpholine (NMM) is necessary to liberate the $N$-terminal secondary amine and enable for catalysis. However, in the absence of trifluoroacetic acid and $N$-methylmorpholine using the 'desalted' peptide the addition products are obtained in the same yields and stereoselectivities. ${ }^{[10,16]}$

\section{Immobilized H-D-Pro-Pro- Glu- $\mathrm{NH}_{2}$ and its Application in a Continuous-Flow System}

The excellent features of H-D-Pro-ProGlu- $\mathrm{NH}_{2}(2)$ such as high catalytic efficiency, high chemoselectivity and no need for additives for the catalysis suggests that the

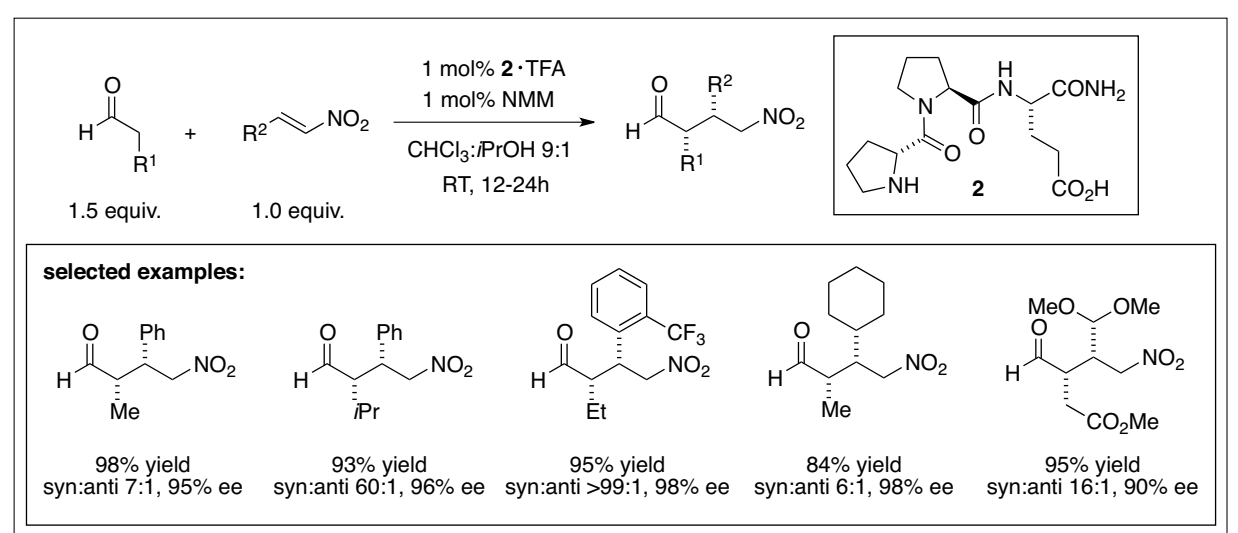

Scheme 2. Conjugate addition reactions of aldehydes to $\beta$-substituted nitroolefins catalyzed by peptide 2.

\begin{tabular}{|c|c|c|c|c|}
\hline 1.5 equiv. 1.0 equiv. & $\begin{array}{c}\text { 1. } 1 \mathrm{~mol} \% 2 \cdot \mathrm{TFA} \\
1 \mathrm{~mol} \% \mathrm{NMM} \\
\mathrm{CHCl}_{3}, \mathrm{RT}\end{array}$ & $\mathrm{NO}_{2}$ & $\begin{array}{l}\text { 1. } \mathrm{H}_{2} \mathrm{Cr}_{2} \mathrm{O}_{7} \\
\text { 2. } 10 \% \mathrm{Ra}-\mathrm{Ni}, \mathrm{H}_{2} \\
\text { 3. } \mathrm{Fmoc}-\mathrm{Cl}\end{array}$ & $\begin{array}{c}\mathrm{R} \\
\gamma^{2} \text {-amino acids }\end{array}$ \\
\hline \multicolumn{5}{|l|}{ selected examples: } \\
\hline $84 \%$ yield, $99 \%$ ee & $85 \%$ yield, $97 \%$ ee & $\begin{array}{c}\text { 67\% yield, 98\% ee } \\
(3 \mathrm{~mol} \% 2)\end{array}$ & $82 \%$ yield, $98 \%$ ee & $82 \%$ yield, $98 \%$ ee \\
\hline
\end{tabular}

Scheme 3. Direct asymmetric catalysis route to $\gamma^{2}$-amino acids. versatility of this peptidic catalyst can be further improved, for example, by immobilization on a solid support. The idea of immobilizing a catalyst on insoluble solid support is highly attractive as it allows in principle the easy recovery and reuse of the catalyst and is therefore important from a practical, economic and environmental viewpoint. ${ }^{[17]}$ However, the successful development of immobilized organocatalysts has proven challenging since catalyst deactivation has often complicated efficient catalyst reuse. This has in particular been a concern for chiral amine-based organocatalysts. ${ }^{[18]}$ To explore the versatility of peptidic catalyst 2 we immobilized the peptide on different solid supports such as cross-linked hydrophobic polystyrene (PS), hydrophilic TentaGel (TG), and polyethylene glycol-polyacrylamide and let the immobilized peptides catalyze the conjugate addition reaction of aldehydes to $\beta$-substituted nitroolefins. The best results were obtained with immobilized H-D-ProPro-Glu-NH - TentaGel (2-TG) which not only provides the desired $\gamma$-nitroaldehydes

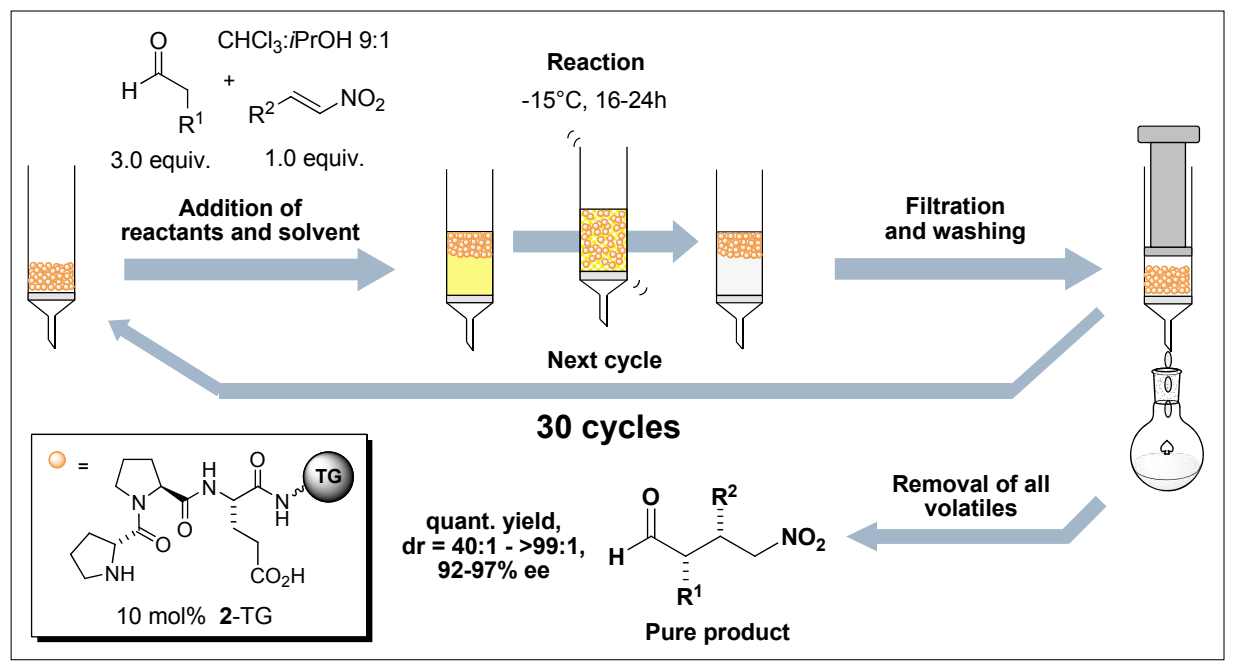

Scheme 4. Conjugate addition reactions with immobilized catalyst 2-TG. 
in excellent yields and stereoselectivities but can also be readily reused for at least 30 reaction and recovery cycles without loss in catalytic activity or stereoselectivity (Scheme 4). ${ }^{[13]}$ The immobilized catalyst can be directly reused after a simple filtration from the reaction products without any reactivation. Most remarkably, reactions catalyzed by 2 -TG proceed so cleanly that the conjugate addition products were isolated easily after simple removal of all volatiles in perfect analytical purities as confirmed by NMR spectroscopic analysis and elemental analysis.

The ease of handling allowed not only a facile scale-up of reactions but also suggested the use of the solid-supported catalyst for the development of a continuous flow system. Indeed, when the parent peptide H-D-Pro-Pro-Glu- $\mathrm{NH}_{2}$ was immobilized on cross-linked PS (2-PS) via an aminohexanoic acid spacer, it proved to be a very efficient catalyst for conjugate addition reactions of aldehydes to $\beta$-substituted nitroolefins in a continuous flow system. ${ }^{[14]}$ Compared to TG as solid support, which showed very good results for the batch reactions, cross-linked PS is more suitable for a flow system since higher catalyst concentrations within a reactor are achievable due to the higher loading capacity and reduced swelling. In addition, using 6-aminohexanoic acid as a linker between the peptide and cross-linked PS improved the stereoselectivities compared to catalyst 2-TG and enabled the reactions to be run at room temperature. The desired $\gamma$-nitroaldehydes were continuously produced in excellent stereoselectivities on a $>450 \mathrm{mmol}$ (>100 gram) scale. The experiments were stopped after a TON of 600 was achieved. At this point the same high activities and stereoselectivities as in the previous runs were observed. For the continuous flow system we chose a simple setup consisting of a bottle containing the substrates connected in series via a piston pump with a column filled with the immobilized catalyst and a bottle to collect the reaction product (Scheme 5). ${ }^{[14]}$ These results highlight the versatility of peptide $\mathrm{H}-\mathrm{D}-\mathrm{Pro}-\mathrm{Pro}-\mathrm{Glu}-\mathrm{NH}_{2}$. Its immobilization on solid support provides an extraordinarily robust, chemoselective and highly efficient catalyst which enables application in a continuous flow system and therefore opens the way for more practical applications of organocatalytic reactions.

\section{1,4-Addition Reactions between Aldehydes and $\alpha, \beta$-disubstituted Nitroolefins}

The high chemoselectivity of peptide H-D-Pro-Pro-Glu-NH $\mathrm{NH}_{2}$ (2) for conjugate addition reactions over competing homo-

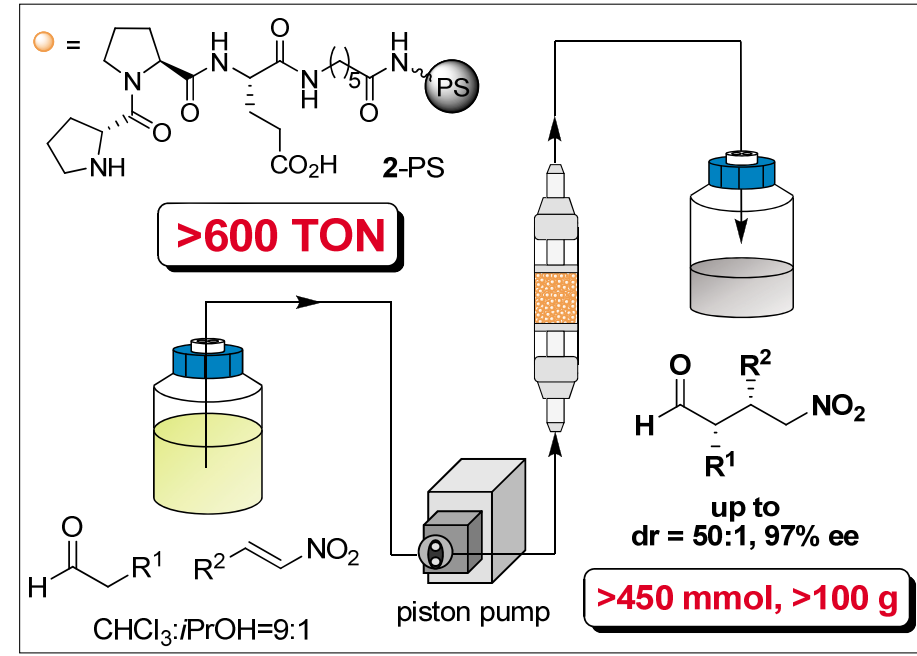

Scheme 5. Synthesis of $\gamma$-nitroaldehydes by continuous flow.

aldol reactions demonstrates that slight modifications in the structure of peptides with the Pro-Pro-Xaa motif easily allow a fine tuning of their chemoselectivity. This suggested to us that this class of peptidic catalysts might contain members suited to catalyze conjugate addition reactions between aldehydes and $\alpha, \beta$-disubstituted nitroolefins. Such nitroolefins are significantly less prone to form conjugate addition products with aldehydes compared to $\beta$-monosubstituted nitroolefins. As a result, a high chemoselectivity for conjugate addition reactions over homo-aldol reactions becomes even more important with such less reactive disubstituted nitroolefins. Reassuringly, a screening of a collection of 15 tripeptides of the type Pro-Pro-Xaa enabled the identification of the peptides

H-Pro-Pro-D-Gln-OH (3) and H-Pro-ProAsn-OH (4) as effective stereoselective catalysts for the conjugate addition of aldehydes to $\alpha, \beta$-disubstituted nitroolefins affording $\gamma$-nitroaldehydes bearing three consecutive stereogenic centers. ${ }^{[15]}$ In the presence of $5 \mathrm{~mol} \%$ of the peptidic catalysts 3 and $\mathbf{4}$ different combinations of aldehydes and $\alpha, \beta$-disubstituted nitroolefins provided the desired products in good to excellent yields and stereoselectivities (Scheme $6)$. The fully substituted $\gamma$-nitroaldehydes can be easily converted into, for example, $\gamma$-butyrolactams or $\gamma$-amino acids with three consecutive stereogenic centers that are useful for medicinal chemistry or foldamer research (Scheme 7). ${ }^{[19,20]}$ For example, $\gamma$-nitroaldehyde 5 was oxidized to $\gamma$-nitrocarboxylic acid $\mathbf{6}$ which then

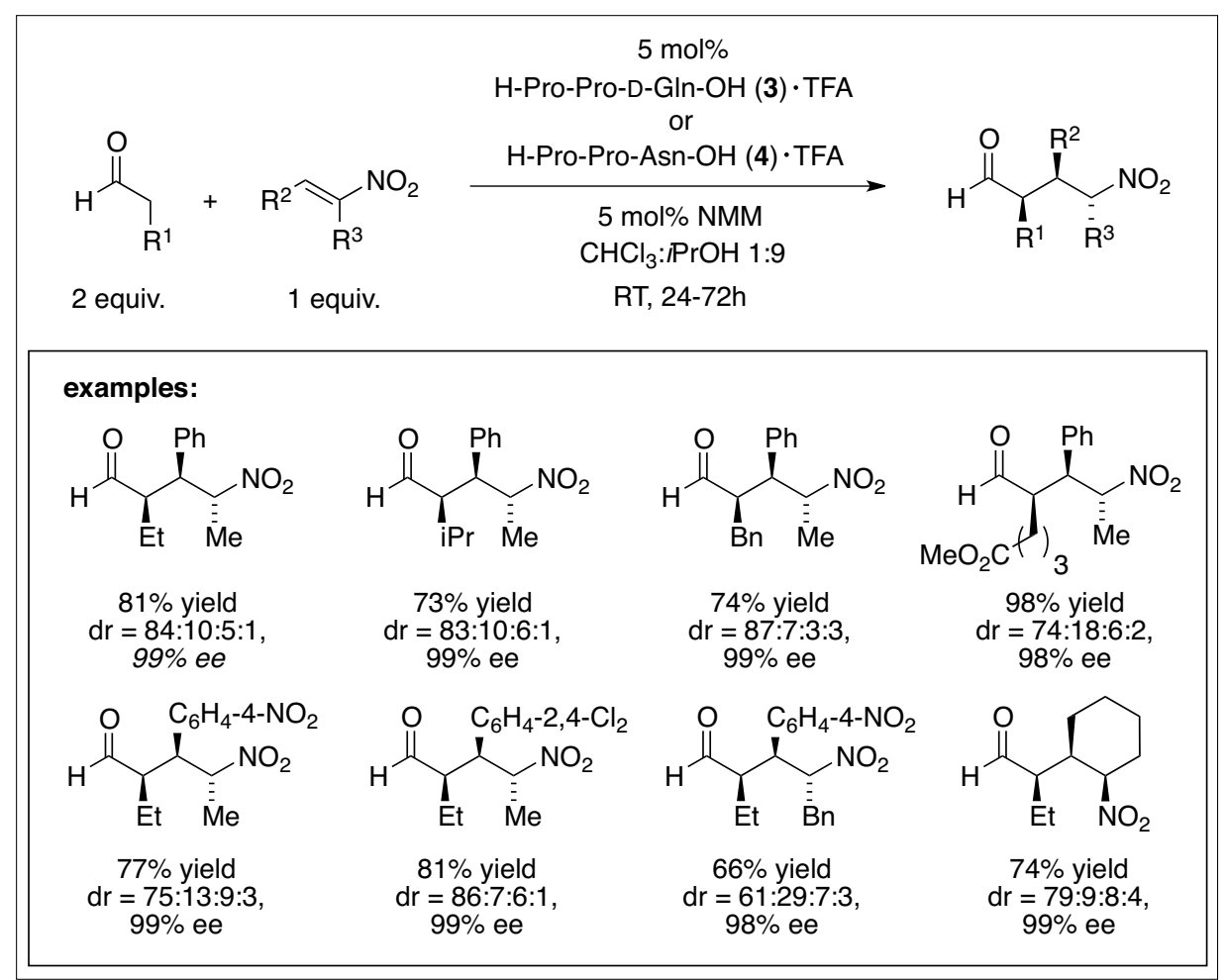

Scheme 6. 1,4-Addition reactions of aldehydes to $\alpha, \beta$-substituted nitroolefins catalyzed by peptides 3 or 4 . 


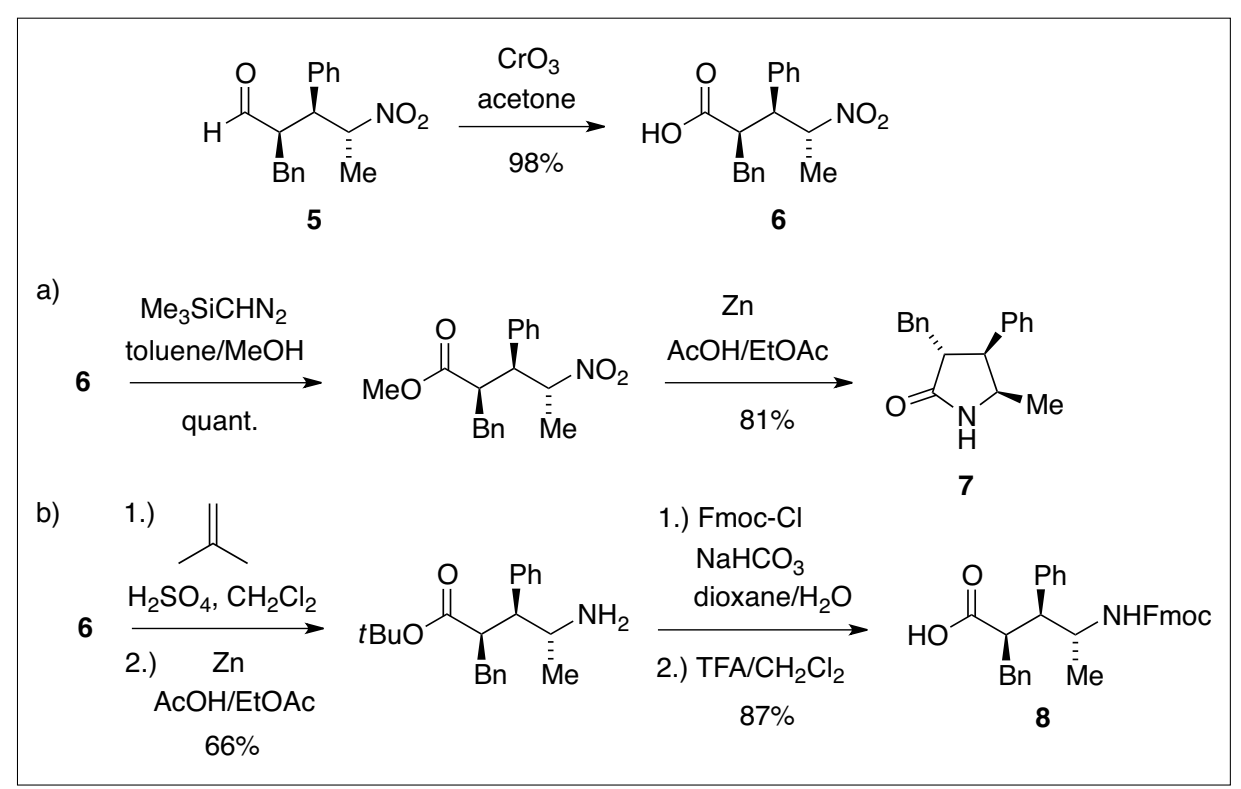

Scheme 7. Synthesis of fully substituted lactam $\mathbf{7}$ and Fmoc-protected $\gamma$-amino acid 8.

served as the common precursor en route to both the $\gamma$-butyrolactam 7 as well as the Fmoc-protected $\gamma$-amino acid $\mathbf{8}$, ready for standard solid-phase peptide synthesis. Lactam 7 was easily prepared in two steps from 6 by esterification with $\mathrm{Me}_{3} \mathrm{SiCHN}_{2}$ followed by reduction of the nitro group using zinc in acetic acid. Fmoc-protected $\gamma$-amino acid $\mathbf{8}$ was obtained in four steps through protection of $\mathbf{6}$ with a bulky tertbutyl ester to prevent upon reduction of the nitro group spontaneous cyclization to lactam 7 followed by Fmoc protection and deprotection of the tert-butyl ester. ${ }^{[15]}$

\section{Conclusions}

Short-chain peptides of the type ProPro-Xaa (Xaa $=$ acidic amino acid) are robust, highly active, chemoselective and stereoselective catalysts for enamine catalysis. For example, peptides H-D-Pro-ProGlu-NH $\mathrm{NH}_{2}$ (2), H-Pro-Pro-D-Gln-OH (3) and H-Pro-Pro-Asn-OH (4) are efficient catalysts for conjugate addition reaction of aldehydes to nitroolefins providing synthetically useful chiral $\gamma$-nitroaldehydes bearing up to three consecutive stereogenic centers in excellent yields and stereoselectivities. An immobilized variant of peptide 2 can be readily reused at least 30 times and was successfully applied for conjugate addition reactions in a continuous flow system.

The research also highlights the versatility of peptidic catalysts of the general type Pro-Pro-Xaa to accommodate different steric and stereoelectronic properties of a given substrate by subtle modifications of the catalyst structure. These features combined with the modular nature and facile synthesis render short peptides interesting alternatives to other organocatalysts. We are currently investigating further electrophiles such as $\beta, \beta$-disubstituted nitroolefins in the peptide-catalyzed conjugate addition reaction providing access to compounds bearing a quaternary stereogenic center.

Received: February 27, 2013

[1] J. Vicario, 'Organocatalytic Enantioselective Conjugate Addition Reactions: A Powerful Tool for the Stereocontrolled Synthesis of Complex Molecules', RSC, Cambridge, 2010.

[2] For recent reviews, see: D. Roca-Lopez, D. Sadaba, I. Delso, R. P. Herrera, T. Tejero, P. Merino, Tetrahedron: Asymm. 2010, 21, 2561; b) S. Mukherjee, J. W. Yang, S. Hoffmann, B. List, Chem. Rev. 2007, 107, 5471.

[3] For selected examples, see: a) J. M. Betancort, C. F. Barbas III, Org. Lett. 2001, 3, 3737; b) A. Alexakis, O. Andrey, Org. Lett. 2002, 4, 3611; c) O. Andrey, A. Alexakis, A. Tomassini, G. Bernardinelli, Adv. Synth. Catal. 2004, 346,
1147; d) Y. Hayashi, H. Gotoh, T. Hayashi, M. Shoji, Angew. Chem. Int. Ed. 2005, 44, 4212; e) W. Wang, J. Wang, H. Li, Angew. Chem. Int. Ed. 2005, 44, 1369; f) C. Palomo, S. Vera, A. Mielgo, E. Gómez-Bengoa, Angew. Chem. Int. Ed. 2006, 45, 5984; g) H. Uehara, C. F. Barbas III, Angew. Chem. Int. Ed. 2009, 48, 9848; h) Y.-F. Ting, C. Chang, R. J. Reddy, D. R. Magar, K. Chen, Chem. Eur. J. 2010, 16, 7030; i) H. Rahaman, Á Madarász, I. Pápai, P. M. Pihko, Angew. Chem. Int. Ed. 2011, 50, 6123.

[4] P. Krattiger, C. McCarthy, A. Pfaltz, H. Wennemers, Angew. Chem. Int. Ed. 2003, 42, 1722.

[5] H. Wennemers, J. Pept. Sci. 2012, 18, 437.

[6] a) P. Krattiger, R. Kovasy, J. D. Revell, S. Ivan, H. Wennemers, Org. Lett. 2005, 7, 1101; b) P. Krattiger, R. Kovasy, J. D. Revell, H. Wennemers, OSAR Comb. Sci. 2005, 24, 1158.

[7] a) J. D. Revell, D. Gantenbein, P. Krattiger, H. Wennemers, Biopolymers 2006, 84, 105; b) J. D. Revell, H. Wennemers, Tetrahedron 2007, 63, 8420; c) J. D. Revell, H. Wennemers, Adv. Synth. Catal. 2008, 350, 1046; d) M. Messerer, H. Wennemers, Synlett 2011, 499.

[8] M. Wiesner, J. D. Revell, S. Tonazzi, H. Wennemers, J. Am. Chem. Soc. 2008, 130, 5610.

[9] M. Wiesner, J. D. Revell, H. Wennemers, Angew. Chem. Int. Ed. 2008, 47, 1871.

[10] M. Wiesner, M. Neuburger, H. Wennemers, Chem. Eur. J. 2009, 15, 10103.

[11] M. Wiesner, G. Upert, G. Angelici, H. Wennemers, J. Am. Chem. Soc. 2010, 132, 6.

[12] M. Wiesner, H. Wennemers, Synthesis 2010, 1568.

[13] Y. Arakawa, M. Wiesner, H. Wennemers, $A d v$. Synth. Catal. 2011, 353, 1201.

[14] Y. Arakawa, H. Wennemers, ChemSusChem 2013, 6, 242.

[15] J. Duschmalé, H. Wennemers, Chem. Eur. J. 2012, 18, 1111 .

[16] J. Duschmalé, J. Wiest, M. Wiesner, H. Wennemers, Chem. Sci. 2013, 4, 1312.

[17] 'Handbook of Asymmetric Heterogeneous Catalysis', Eds. K. Ding, Y. Uozumi, Wiley$\mathrm{VCH}$, Weinheim, 2008.

[18] For recent examples of immobilized chiral amine-based organocatalysts, see: a) L. Tuchman-Shukron, S. J. Miller, M. Portnoy, Chem. Eur. J. 2012, 18, 2290; b) C. Ayats, A. H. Henseler, M. A. Pericàs, ChemSusChem 2012, 5, 320; c) E. Alza, S. Sayalero, P. Kasaplar, D. Almaşi, M. A. Pericàs, Chem. Eur. J. 2011, 17, 11585; d) M. Gruttadauria, A. M. P. Salvo, F. Giacalone, P. Agrigento, R. Noto, Eur. J. Org. Chem. 2009, 5437.

[19] For a review, see: K. Gajcy, S. Lochynski, T. Librowski, Curr. Med. Chem. 2010, 17, 2338.

[20] a) D. Seebach, M. Brenner, M. Rueping, B. Schweizer, B. Jaun, Chem. Commun. 2001, 207; b) D. Seebach, M. Brenner, M. Rueping, B. Jaun, Chem. Eur. J. 2002, 8, 573; c) D. Seebach, D. F. Hook, A. Glättli, Biopolymers 2006, 84, 23 ; d) P. G. Vasudev, S. Chatterjee, N. Shamala, P. Balaram, Chem. Rev. 2011, 111, 657; e) S. H. Gellman, Acc. Chem. Res. 1998, 31, 173. 